\title{
Prenatal Head Growth and White Matter Injury in Hypoplastic Left Heart Syndrome
}

\author{
ROBERT B. HINTON, GREGOR ANDELFINGER, PRIYA SEKAR, ANDREA C. HINTON, ROXANNE L. GENDRON, \\ ERIK C. MICHELFELDER, YVES ROBITAILLE, AND D. WOODROW BENSON
}

\begin{abstract}
Division of Cardiology [R.B.H., P.S., E.C.M., D.W.B.], Cincinnati Children's Hospital Medical Center, Cincinnati, Ohio 45229; Divisions of Cardiovascular Genetics [G.A.] and Pathology [R.L.G., Y.R.], University of Montreal, Quebec, Canada H3T 1C5; Division of Maternal Fetal Medicine [A.C.H.], Good Samaritan Hospital, Cincinnati, Ohio 45220
\end{abstract}

\begin{abstract}
Children with hypoplastic left heart syndrome (HLHS) have an increased prevalence of central nervous system (CNS) abnormalities. The extent to which this problem is due to CNS maldevelopment, prenatal ischemia, postnatal chronic cyanosis and/or multiple exposures to cardiopulmonary bypass is unknown. To better understand the etiology of CNS abnormalities in HLHS, we evaluated 68 neonates with HLHS; in 28 cases, both fetal ultrasound and echocardiogram data were available to assess head size, head growth and aortic valve anatomy (atresia or stenosis). In addition, we evaluated neuropathology in 11 electively aborted HLHS fetuses. The mean head circumference percentile in HLHS neonates was significantly smaller than HLHS fetuses ( $22 \pm 2 \%$ versus $40 \pm 4 \%$, $p<0.001$ ). A significant decrease in head growth, defined as a $50 \%$ reduction in head circumference percentile, was observed in half $(14 / 28)$ of HLHS fetuses and nearly a quarter (6/28) were already growth restricted $(\leq 10 \%)$ at the time of initial evaluation. Brains from HLHS fetuses demonstrated chronic diffuse white matter injury of varying severity. These patterns of prenatal head growth and brain histopathology identify a spectrum of abnormal CNS development and/or injury in HLHS fetuses. (Pediatr Res 64: 364-369, 2008)
\end{abstract}

$\mathrm{H}$ ypoplastic left heart syndrome (HLHS, MIM\#241550) remains a significant cause of infant mortality and long-term morbidity despite significant advances in diagnosis and treatment (1-4). HLHS patients have an increased prevalence of central nervous system (CNS) abnormalities, which have been attributed to chronic cyanosis and multiple exposures to cardiopulmonary bypass $(5,6)$. However, results from several studies indicate that in approximately one half of cases, CNS abnormalities are present at birth $(4,7-10)$ and may manifest as reduced head circumference or microcephaly in the neonate $(10-12)$. It is unknown at what stage of development these CNS abnormalities occur and whether this represents a primary CNS developmental abnormality or a secondary insult resulting from alterations in cerebral blood flow due to HLHS.

Little is known of the etiology of HLHS. Evidence supporting both genetic (13-15) and epigenetic (16-18) factors has been reported. A widely accepted hypothesis is that HLHS develops as a result of alterations in embryonic intracardiac

Received January 25, 2008; accepted May 23, 2008.

Correspondence: Robert B. Hinton, Jr., M.D., Division of Cardiology, MLC 2003, 3333 Burnet Ave; Cincinnati, OH 45229-3039; e-mail: Robert.Hinton@cchmc.org

Supported by NIH HL085122 (RBH), CIHR GMHD79045 (GA) and NIH HL069712 (DWB). blood flow, such as narrowing of the foramen ovale and aortic stenosis (AS) (16-18). Longitudinal studies of the fetus have shown that AS is part of the in utero natural history of HLHS $(19,20)$; for this reason, there has been considerable interest in developing indications for fetal intervention for AS $(21,22)$. By adversely affecting antegrade aortic blood flow, early progression of aortic valve obstruction may reduce cerebral blood flow, thereby adversely impacting CNS development and subsequent head growth. This possibility is supported by identification of white matter injury, reminiscent of periventricular leukomalacia, in term neonates with HLHS before surgical intervention (23-25). Neuropathologic findings have also identified white matter injury in postoperative HLHS neonates (26); however, neuropathology has not been examined in HLHS fetuses.

We sought to examine head size and growth in HLHS and AS fetuses and neonates. We hypothesized that CNS abnormalities present at birth can be detected at midgestation. We found that some HLHS and AS fetuses already have small head size at midgestation. However, the majority has normal head size, but half of these fetuses subsequently demonstrate poor head growth. In addition, some HLHS fetuses demonstrate white matter injury at midgestation. Taken together, these findings suggest there is a spectrum of abnormal CNS development in HLHS and AS fetuses. Identification of specific head growth patterns may impact the clinical management of HLHS and AS.

\section{METHODS}

Study population. Neonates ( $<28 \mathrm{~d}$ of age) diagnosed with HLHS or isolated AS from January 1998 through December 2006 were identified from a database within the Division of Cardiology at Cincinnati Children's Hospital Medical Center. HLHS was defined as atresia or stenosis of the aortic and mitral valves, and hypoplasia of the left ventricle and ascending aorta $(18,27)$. AS was defined as obstruction at the level of the aortic valve with a mean pressure gradient $\geq 25 \mathrm{~mm} \mathrm{Hg}$ (28) in the absence of other cardiovascular malformation. Neonates born prematurely ( $<37$ wk gestation), the product of multiple gestation pregnancies, or with a known genetic syndrome (e.g. Turner syndrome) were excluded. The Institutional Review Boards at Cincinnati Children's Hospital Medical Center and Good Samaritan Hospital (Cincinnati, OH) approved this study and deemed it consent exempt.

A complete neuropathologic evaluation was performed in a separate cohort of electively aborted HLHS fetuses identified from a database within the Division of Pathology at Sainte Justine Hospital. Specimens were collected

Abbreviations: AS, aortic stenosis; HLHS, hypoplastic left heart syndrome 
between January 1998 and December 2006. A fetal echocardiographic diagnosis of HLHS as defined above was confirmed by pathologic evaluation. Fetuses with a known genetic syndrome were excluded. The Institutional Review Board at St Justine Hospital approved this study and deemed it consent exempt.

Anthropometric data. Medical records were reviewed to identify those HLHS patients with both fetal ultrasound and echocardiogram data. Anthropometric data were obtained at two time points (fetal and neonatal); the earliest available ultrasounds were used. Head circumference was evaluated using normal fetal and newborn head circumference percentiles adjusted for gestational age and gender (29-31), and "normal" size was considered between the 11th and 89th percentile. Growth restriction was defined as a head circumference or weight $\leq$ the tenth percentile. Microcephaly was defined as a head circumference $\leq$ the third percentile. A significant decrease in head growth was defined arbitrarily as $\geq 50 \%$ reduction in head circumference percentile. Proportionate ("symmetric") head size, defined as normal head size as a ratio of normal somatic size, was evaluated using the head circumference to abdominal circumference ratio (HC/AC) in fetuses $(32,33)$, and the head volume $\left(\mathrm{HC}^{3}\right)$ to weight ratio $\left(\mathrm{HC}^{3} / \mathrm{Wt}\right)$ in neonates $(31,34)$. Since head size in HLHS neonates clusters in the low-normal range $(10,12)$, head size was considered disproportionately small if it was more than one SD below the mean. Placental function was evaluated by calculating umbilical artery resistance index (35).

Echocardiographic data. The diagnosis of HLHS or AS was based on the neonatal echocardiogram; however, both neonatal and fetal echocardiogram reports were reviewed to evaluate aortic valve anatomy. To determine the relative effects of antegrade aortic blood flow on head growth, aortic valve anatomy in HLHS neonates and fetuses was used to stratify into subgroups (atresia or stenosis); head size and head growth were compared with a cohort of AS patients.

Pathology data. Fetal brains were evaluated using a standardized neuropathologic protocol $(36,37)$. Immunohistochemistry was performed to assess CNS white matter injury using antibodies directed against glial fibrillary acidic protein (GFAP, Dako) for the detection of reactive astrocytes, and CD68 (Dako) for detection of activated microglia (26,37). To grade the severity of fetal CNS white matter injury, a classification system similar to established neonatal systems was developed $(26,36,37)$.

Statistical analysis. $t$ Test or Fisher's exact test were used to compare groups as appropriate. A $p$-value $\leq 0.05$ was considered significant.

\section{RESULTS}

Study population. A total of 86 HLHS neonates were identified; 14 cases were excluded due to prematurity (9), genetic syndromes (4) or a multiple gestation pregnancy (1). A total of 36 AS neonates were identified; 2 cases were excluded due to prematurity (1) or a genetic syndrome (1). Neonatal head circumference data were available and analyzed in 68/72 (94\%) HLHS and 32/34 (94\%) AS patients. Fetal ultrasound and echocardiogram data were available in 28/68 (41\%) HLHS and 6/32 (19\%) AS patients. HLHS with aortic atresia was present in 51/68 (75\%) neonates and $19 / 28(68 \%)$ fetuses. Cardiac anatomy from the fetal echocardiogram was consistent with the neonatal echocardiogram in 24/28 (86\%) HLHS patients. However, in 4/28 (14\%) HLHS neonates the severity of disease progressed in utero.
This included 3/32 (9\%) fetuses with AS that progressed to HLHS (two with aortic atresia and one with AS), and 1 fetus with HLHS with AS that progressed to HLHS with aortic atresia at birth.

Neonatal anthropometrics. Neonatal head circumference measurements were analyzed in 68 HLHS (44 male; 24 female) and 32 AS (25 male; 7 female) patients (Fig. 1). The gender, aortic valve morphology and anthropometric measures were the same in neonates with and without fetal data (data not shown). The average head circumference percentile for HLHS neonates was smaller than AS neonates $(p<0.001$, Table 1), consistent with previous findings $(10,12)$. Reduced head circumference was evident in HLHS neonates as microcephaly (13\%) or head growth restriction (40\%) (Fig. 1). When HLHS neonates were stratified based on aortic valve anatomy, the mean head circumference percentile was smaller in HLHS with aortic atresia than HLHS with AS $(p<0.05$, Table 1), suggesting that small head size is related in part to the absence of antegrade aortic blood flow. However, reduced head circumference was also present in AS neonates as microcephaly $(3 / 32,9 \%)$ or head growth restriction $(5 / 32,16 \%)$, suggesting factors other than absent antegrade blood flow contribute to small head size. As previously reported, somatic growth restriction was present in $16 \%$ of HLHS neonates and $13 \%$ of AS neonates (38), but the average weights of HLHS neonates $(3253 \pm 508 \mathrm{~g}$, mean percentile $38 \%)$ and AS

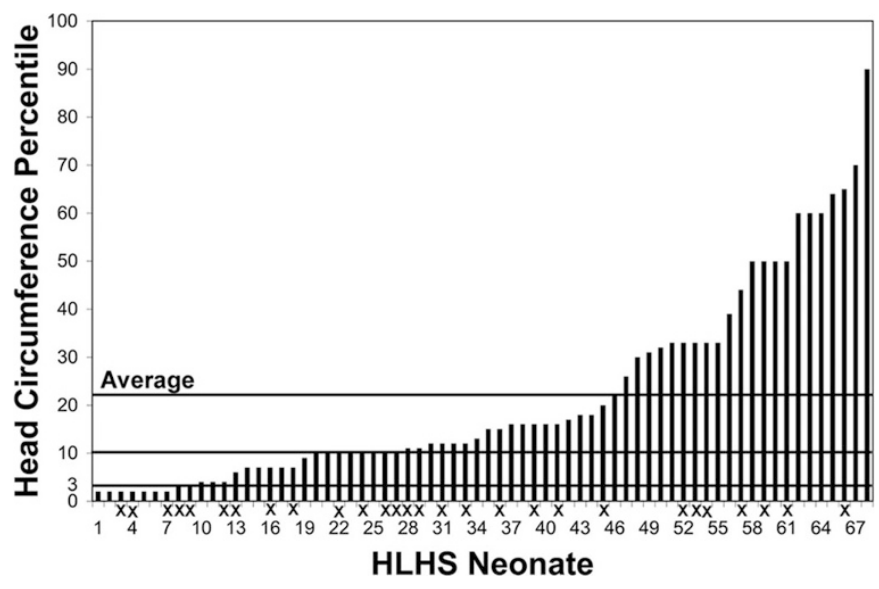

Figure 1. Neonatal HLHS study population. Head circumference percentile in 68 HLHS neonates with those patients also analyzed as fetuses indicated by an " $X$ ". The average head circumference percentile in this cohort was $22 \%$. A significant number of neonates have microcephaly $(\leq 3 \%)$ and head growth restriction $(\leq 10 \%)$.

Table 1. Fetal and neonatal anthropometrics in HLHS and AS

\begin{tabular}{|c|c|c|c|c|c|c|}
\hline & $\begin{array}{c}\text { Fetal } \\
\text { HC }(\%)\end{array}$ & $\begin{array}{c}\text { Fetal } \\
\text { HC/AC }(z)\end{array}$ & $\begin{array}{l}\text { Neonatal } \\
\text { HC }(\mathrm{cm})\end{array}$ & $\begin{array}{c}\text { Neonatal } \\
\text { HC }(\%)\end{array}$ & $\begin{array}{l}\text { Neonatal } \\
\mathrm{HC}^{3} / \mathrm{WT}\end{array}$ & $\begin{array}{c}\text { Neonatal } \\
\mathrm{HC}^{3} / \mathrm{WT}(z)\end{array}$ \\
\hline All HLHS & $40 \pm 4$ & $-0.1 \pm 0.1$ & $33.7 \pm 0.2$ & $22 \pm 2 *$ & $11.9 \pm 0.1$ & $-0.7 \pm 0.1$ \\
\hline HLHS: AA & $38 \pm 5$ & $-0.1 \pm 0.1$ & $33.5 \pm 0.20$ & $19 \pm 3 *$ & $11.9 \pm 0.2$ & $-0.7 \pm 0.1$ \\
\hline HLHS: AS & $49 \pm 10$ & $-0.4 \pm 0.3$ & $34.2 \pm 0.4$ & $29 \pm 5 \dagger$ & $12.0 \pm 0.2$ & $-0.7 \pm 0.2$ \\
\hline AS & $34 \pm 11$ & $-0.5 \pm 0.5$ & $34.9 \pm 0.3 \neq$ & $39 \pm 5 \ddagger$ & $12.6 \pm 0.3 \ddagger$ & $-0.2 \pm 0.2$ \\
\hline
\end{tabular}

Mean \pm SEM.

HC, head circumference; AC, abdominal circumference; $z$, $z$-score.

$* p<0.05$ Fetal $v$ s Neonatal.

$\dagger p<0.05$ HLHS with aortic atresia (AA) vs HLHS with aortic stenosis (AS).

$\$ p<0.05$ All HLHS vs AS. 
neonates $(3326 \pm 410 \mathrm{~g}$, mean percentile $41 \%)$ were not different $(p=\mathrm{NS})$. Among neonates with microcephaly, 6/9 were growth restricted in the HLHS cohort, whereas 2/3 were growth restricted in the AS cohort. Disproportionately small head size was demonstrated in 38\% of HLHS neonates $(73 \%$ had aortic atresia) and $25 \%$ of AS neonates.

Fetal anthropometrics. Head growth was evaluated in 28 HLHS and 6 AS fetuses at 17-36 wk gestation (Table 1, Fig. 2). HLHS fetuses had a significantly larger mean head circumference percentile than HLHS neonates $(p<0.001$, Table 1); specifically, HLHS fetuses were less likely to have micro-
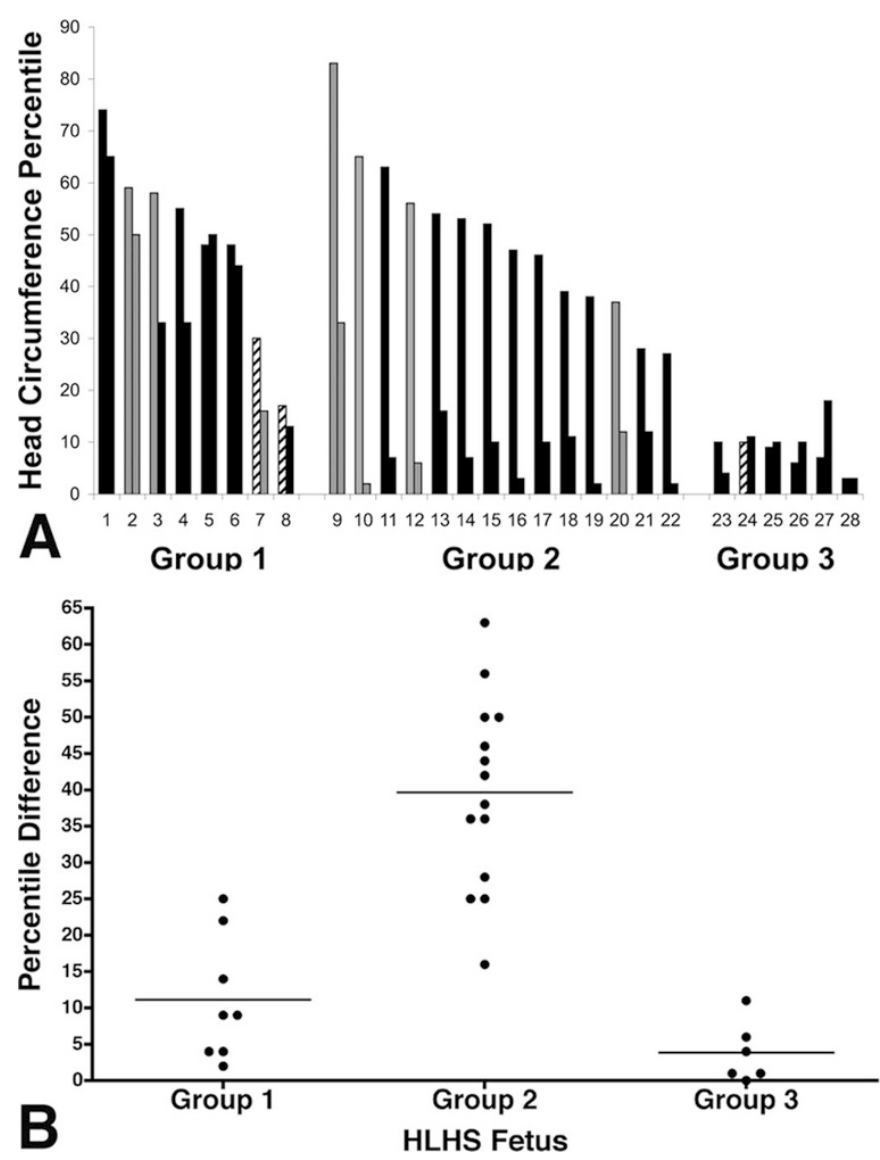

Figure 2. HLHS prenatal head growth. Head circumference percentile in 28 HLHS patients at fetal (left bar) and neonatal (right bar) time points (A). Patients are divided into three subgroups: normal head size and growth (Group 1, infants 1-8), normal head size and diminished head growth (Group 2, infants 9-22), and small head size (Group 3, infants 23-28). Black bars represent HLHS with aortic atresia; gray bars HLHS with aortic stenosis; and hatched bars AS. Head circumference percentile difference for each patient by subgroup is shown $(B)$. cephaly ( $4 \%$ versus $13 \%)$, head growth restriction ( $22 \%$ versus $40 \%$ ) or disproportionately small head size (4\% versus $38 \%$ ). Taken together, these findings suggest that HLHS fetuses are more likely to have normal head size than HLHS neonates. Similarly, AS fetuses tended to have normal head size although 1/6 had microcephaly.

Prenatal head growth. Prenatal head growth was assessed in HLHS and AS fetuses by examining the difference in head circumference percentiles at fetal and neonatal time points (Fig. 2). Among HLHS fetuses, 22/28 (78\%) had normal head size; however, only $8 / 28$ (29\%) had normal head size and normal head growth. A total of 14/28 (50\%) had normal head size and diminished head growth, and 6/28 (22\%) already demonstrated head growth restriction at midgestation (Table 2, Fig. 2). Diminished head growth occurred in 7/14 (50\%) HLHS fetuses in the second trimester ( $<27$ wk gestation) and $7 / 14$ in the third trimester ( $\geq 27$ wk gestation), demonstrating that diminished head growth is not restricted to either the second or third trimester. Importantly, umbilical artery Doppler data were available in 22/28 HLHS and 5/6 AS fetuses; the calculated umbilical artery resistance index was normal for gestational age in all cases, suggesting that any growth restriction present was not due to placental insufficiency. Since progression of aortic valve obstruction may reduce cerebral blood flow thereby impacting prenatal CNS development and subsequent head growth, the relative influence of antegrade flow (atresia versus stenosis) on prenatal head growth was assessed. Among HLHS fetuses with normal head size and growth, 4/8 (50\%) had HLHS with aortic atresia, whereas 15/20 (75\%) of those with either small head size or reduced head growth had HLHS with aortic atresia $(p=0.37, \mathrm{NS})$. These findings suggest that small head size and reduced head growth in this small cohort are not associated with aortic atresia or absence of antegrade blood flow. Interestingly, 2/6 AS fetuses had diminished head growth, both occurring in the third trimester.

Neuropathology. Comprehensive neuropathologic evaluations were performed in 14 HLHS fetuses; three cases were excluded due to genetic syndromes. Of the 11 HLHS fetuses analyzed, six had aortic atresia and five had AS; all fetuses were 19-22 wk gestation. Examination of gross brain anatomy was normal in 10 fetuses; hydrocephaly was present in one fetus. By gross and histologic examination, there was no evidence of migrational or opercularization defects, and cortical development staging for gestational age was normal in all cases (36). Brain weights adjusted for gestational age were normal in 18/20 and decreased in 2/20 (10\%) HLHS fetuses evaluated by Andelfinger et al. (unpublished data), consistent

Table 2. Patterns of head growth in HLHS fetuses

\begin{tabular}{|c|c|c|c|c|}
\hline & $\begin{array}{c}\text { Fetal } \\
\text { HC }(\%)\end{array}$ & $\begin{array}{l}\text { Neonatal } \\
\mathrm{HC}(\mathrm{cm})\end{array}$ & $\begin{array}{l}\text { Neonatal } \\
\text { HC }(\%)\end{array}$ & $p$ \\
\hline $\begin{array}{l}\text { Normal head size } \\
\text { Normal head growth }\end{array}$ & $\begin{array}{l}48 \pm 18 \\
(17-74)\end{array}$ & $\begin{array}{c}34.9 \pm 1.1 \\
(33.0-36.0)\end{array}$ & $\begin{array}{l}38 \pm 18 \\
(13-65)\end{array}$ & 0.12 \\
\hline $\begin{array}{l}\text { Normal head size } \\
\text { Reduced head growth }\end{array}$ & $\begin{array}{l}49 \pm 15 \\
(27-83)\end{array}$ & $\begin{array}{l}32.6 \pm 1.5 \\
(29.5-35.0)\end{array}$ & $\begin{array}{l}10 \pm 8 \\
(2-33)\end{array}$ & $<0.001$ \\
\hline $\begin{array}{l}\text { Small head size } \\
\text { Anticipated head growth }\end{array}$ & $\begin{array}{l}8 \pm 3 \\
(3-10)\end{array}$ & $\begin{array}{l}33.2 \pm 1.0 \\
(32.0-34.5)\end{array}$ & $\begin{array}{l}9 \pm 5 \\
(3-18)\end{array}$ & 0.23 \\
\hline
\end{tabular}

Mean \pm SD (range). 
with the normal head size and ultrasound findings of the current study. However, according to a fetal CNS white matter injury working classification scheme (Table 3), all HLHS fetuses demonstrated varying degrees of white matter injury. Both GFAP and CD68 expression was significantly increased in HLHS CNS tissues compared with age matched controls (Fig. 3), consistent with chronic white matter injury (37). The white matter injury was localized to the deep and intermediate white matter with widespread but multifocal involvement of

Table 3. Classification and incidence of fetal CNS white matter injury

\begin{tabular}{|c|c|c|c|}
\hline Stage & Findings & Affected & Control \\
\hline 0 & $\begin{array}{l}\text { Normal sub-ependymal plate thickness } \\
\text { with minimal perivascular microglia } \\
\text { or reactive astrocytic hypertrophy }\end{array}$ & $0 / 11$ & $5 / 6$ \\
\hline 1 & $\begin{array}{l}\text { Thickened, gliotic sub-ependymal } \\
\text { plate with multifocal microglia or } \\
\text { macrophagic response within } \\
\text { sub-ependymal plate and } \\
\text { surrounding deep white matter }\end{array}$ & $0 / 11$ & $0 / 6$ \\
\hline 2 & $\begin{array}{l}\text { Perivascular chronic inflammation } \\
\text { involving lymphomononuclear cells. } \\
\text { Multifocal astrocytic hypertrophy, } \\
\text { reactive type }\end{array}$ & $0 / 11$ & $1 / 6$ \\
\hline 3 & $\begin{array}{l}\text { Confluence of chronic inflammation } \\
\text { and reactive gliosis extending into } \\
\text { the intermediate white matter }\end{array}$ & $\begin{array}{c}1 / 11 \\
(0 \mathrm{AA}, 1 \mathrm{AS})\end{array}$ & $0 / 6$ \\
\hline 4 & $\begin{array}{l}\text { Reactive gliosis extending into the } \\
\text { superficial white matter }\end{array}$ & $\begin{array}{c}5 / 11 \\
(3 \mathrm{AA}, 2 \mathrm{AS})\end{array}$ & $0 / 6$ \\
\hline 5 & $\begin{array}{l}\text { Single or multiple infarcts or } \\
\text { hemorrhage }\end{array}$ & $\begin{array}{c}5 / 11 \\
(3 \mathrm{AA}, 2 \mathrm{AS})\end{array}$ & $0 / 6$ \\
\hline 6 & $\begin{array}{l}\text { Extensive reactive gliosis, chronic } \\
\text { inflammation, and remote infarcts } \\
\text { and scattered cavitation }\end{array}$ & $0 / 11$ & $0 / 6$ \\
\hline
\end{tabular}

Each stage includes findings from previous stage. HLHS with aortic atresia (AA); HLHS with aortic stenosis (AS).

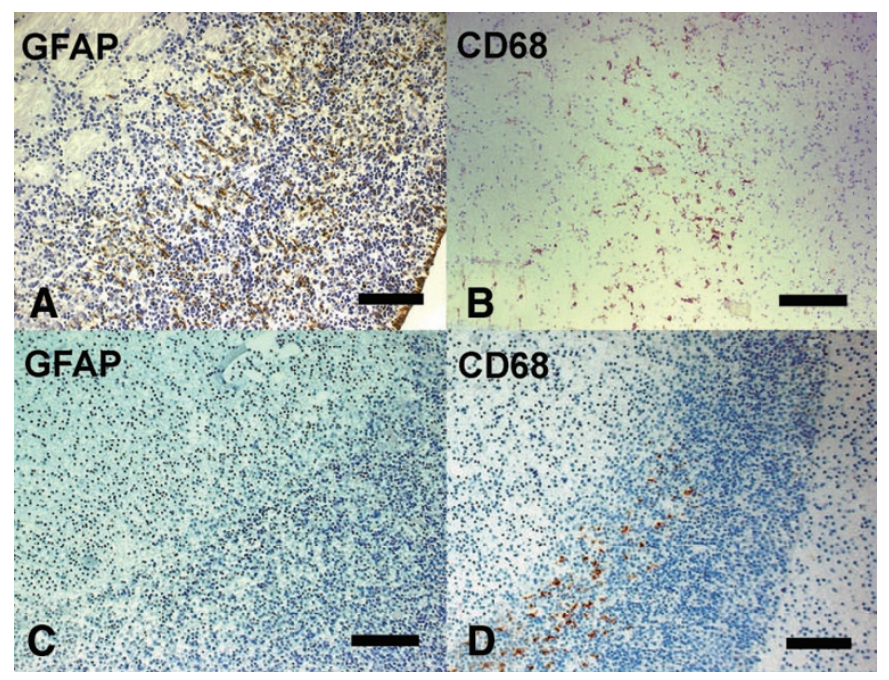

Figure 3. White matter injury in HLHS fetuses. Neuropathologic evaluation using antibodies directed against GFAP and CD68 in representative sections of the germinal plate and adjacent white matter in a 22-wk HLHS fetus $(A, B)$ and a 22 -wk Control fetus $(C, D)$. In the HLHS fetus, there are extensive reactive astrocytes $(A)$ and scattered activated microglia $(B)$ consistent with white matter injury, whereas in the Control fetus, there is no reactive astrocytic hypertrophy $(C)$ and minimal microglia $(D)$. Scale bar $=100 \mu \mathrm{m}$; Images at $200 \mathrm{X}$. adjacent CNS structures. Infarcts, which have been identified in HLHS neonates after surgery, were not present in HLHS fetuses (26). In addition, all HLHS fetuses demonstrated gray matter injury (data not shown). Aortic valve anatomy (atresia versus stenosis) did not appear to correlate with the degree of white matter injury in this small sample (Table 3).

\section{DISCUSSION}

The findings of the current study identify three patterns of prenatal head growth in HLHS fetuses. Although most HLHS fetuses have normal and proportionate head size at midgestation, during the latter half of gestation they develop reduced head size and disproportionate head growth restriction. Interestingly, brains of HLHS fetuses demonstrate varying degrees of white matter injury despite normal brain weight. These patterns of prenatal head growth and brain morphology suggest that there is a spectrum of abnormal CNS development in HLHS fetuses. The extent to which these CNS abnormalities are primarily related to the underlying cause of HLHS or secondarily related to blood flow abnormalities resulting from the heart malformation is unknown. However, stratification of HLHS fetuses based on head size, brain injury and growth potential may have significant clinical implications for both treatment strategies and outcome assessment.

In the HLHS fetus and neonate, intracardiac blood flow alterations are associated with decreased cerebral blood flow despite autoregulation (11), and reduced cerebral blood flow during CNS development may result in poor head growth and small head size in neonates. However, the presence of normal head size and growth in some HLHS fetuses with aortic atresia, the lack of correlation between head size or growth and aortic valve anatomy, and the presence of small head size and poor head growth in some AS fetuses with relatively mild blood flow perturbations, does not support a strong association between absent antegrade aortic blood flow and the development of small head size, raising the possibility that other factors, e.g. genetic, contribute to both cardiac and CNS development. Taken together, these findings potentially support a complex etiology with genetic (13-15) and epigenetic (16-18) factors contributing to the pathogenesis of CNS abnormalities in HLHS and AS.

Neuropathologic evaluation of HLHS fetuses demonstrated chronic white matter injury, consistent with previous studies in neonates $(8,24)$. Importantly, the findings of this study identify white matter injury in HLHS fetuses in a pattern different from that which is typically seen in premature infants with normal hearts (25); specifically, the white matter injury is relatively severe and widespread suggesting these observations cannot be explained by altered cerebral blood flow alone (39). However, to date there have been no studies correlating fetal CNS pathologic and imaging findings, which has limited the extension of these findings to longitudinal studies of neurocognitive outcomes. Further, it remains to be determined the degree to which white matter injury correlates with persistent neurocognitive deficit; however, advances in magnetic resonance imaging suggest this may be a feasible modality to assess the fetal CNS $(23,40,41)$. 
There is substantial growth and development of the CNS during embryonic development concurrent with primary cardiac morphogenesis (42). The CNS proliferative phase, during which time there is abundant cell division and the majority of brain growth occurs, overlaps with valvulogenesis and extends to approximately $20 \mathrm{wk}$ gestation (43). Brain growth after this time is attributed to radial migration of progenitor cells to form the cerebral cortex in an "inside-out" manner $(43,44)$. Regional cerebral blood flow in the fetus is preferentially distributed to the brain stem, in contrast to postnatal life when it is directed toward the cortex (45); this time course may make cortical white matter particularly vulnerable to blood flow alterations during gestation. Taken together, the dynamic time course of CNS development and blood flow distribution raises the possibility that the pathogenesis underlying head growth restriction in HLHS fetuses may vary depending on the nature of the genetic abnormality and the timing of the epigenetic insult. Further studies are warranted to determine how to distinguish these subgroups of HLHS fetuses.

The ability to identify subgroups of HLHS in utero based on head size and growth may redefine risk stratification potentially impacting reproductive decision-making, therapeutic intervention and predicting neurodevelopmental outcome. In addition, grouping of HLHS and AS fetuses based on CNS phenotype may impact indications for fetal cardiac intervention. Although fetuses with small heads at midgestation may already be at increased risk for adverse CNS outcomes, a prospective study is needed to determine which fetuses are at risk for poor head growth and may benefit from fetal intervention to improve cerebral blood flow, thereby preserving head growth and preventing unfavorable CNS outcomes. As the genetic basis of HLHS is elucidated, informative genotypephenotype relationships may emerge that can be identified in the fetal period and significantly impact clinical decisions.

This study has notable limitations. First, the study design is observational limiting our ability to test mechanistic hypotheses. Second, fetal data were not available in 59\% of HLHS patients. HLHS is increasingly diagnosed in utero, however, approximately one half of HLHS patients and the vast majority of AS patients are diagnosed postnatally. In this pilot study, comparison of baseline characteristics between HLHS neonates with and without fetal data were similar suggesting these results may be generalizable; however, the size of both the HLHS and AS cohorts is small raising the possibility that these findings may not be representative of all patients with HLHS or AS. Ultimately, a large prospective study will be necessary to control for these limitations.

Acknowledgments. We thank Wendi Long, Carol Schaefer, Meredith Kinsel and Cheri Franklin for their assistance.

\section{REFERENCES}

1. Rogers BT, Msall ME, Buck GM, Lyon NR, Norris MK, Roland JM, Gingell RL, Cleveland DC, Pieroni DR 1995 Neurodevelopmental outcome of infants with hypoplastic left heart syndrome. J Pediatr 126:496-498

2. Wernovsky G, Stiles KM, Gauvreau K, Gentles TL, duPlessis AJ, Bellinger DC, Walsh AZ, Burnett J, Jonas RA, Mayer JE Jr, Newburger JW 2000 Cognitive development after the Fontan operation. Circulation 102:883-889
3. Tworetzky W, McElhinney DB, Reddy VM, Brook MM, Hanley FL, Silverman NH 2001 Improved surgical outcome after fetal diagnosis of hypoplastic left heart syndrome. Circulation 103:1269-1273

4. Wernovsky G 2006 Current insights regarding neurological and developmental abnormalities in children and young adults with complex congenital cardiac disease. Cardiol Young 16:92-104

5. Newburger JW, Jonas RA, Wernovsky G, Wypij D, Hickey PR, Kuban KC, Farrell DM, Holmes GL, Helmers SL, Constantinou J, Carrazana E, Barlow JK, Walsh AZ, Lucius KC, Share JC, Wessel DL, Hanley FL, Mayer JE, Castenada AR, Ware JH 1993 A comparison of the perioperative neurologic effects of hypothermic circulatory arrest versus low-flow cardiopulmonary bypass in infant heart surgery. N Engl J Med 329:1057-1064

6. Bellinger DC, Jonas RA, Rappaport LA, Wypij D, Wernovsky G, Kuban KC, Barnes PD, Holmes GL, Hickey PR, Strand RD, Walsh AZ, Helmers SL, Constantinou JE, Carrazana EJ, Mayer JE, Hanley FL, Castenada AR, Ware JH, Newburger JW 1995 Developmental and neurologic status of children after heart surgery with hypothermic circulatory arrest or low-flow cardiopulmonary bypass. N Engl J Med 332:549-555

7. Natowicz M, Chatten J, Clancy R, Conard K, Glauser T, Huff D, Lin A, Norwood W, Rorke LB, Uri A, Weinberg P, Zackai E, Kelley RI 1988 Genetic disorders and major extracardiac anomalies associated with the hypoplastic left heart syndrome. Pediatrics 82:698-706

8. Glauser TA, Rorke LB, Weinberg PM, Clancy RR 1990 Acquired neuropathologic lesions associated with the hypoplastic left heart syndrome. Pediatrics 85:991-1000

9. Glauser TA, Rorke LB, Weinberg PM, Clancy RR 1990 Congenital brain anomalies associated with the hypoplastic left heart syndrome. Pediatrics 85:984-990

10. Rosenthal GL 1996 Patterns of prenatal growth among infants with cardiovascular malformations: possible fetal hemodynamic effects. Am J Epidemiol 143:505-513

11. Donofrio MT, Bremer YA, Schieken RM, Gennings C, Morton LD, Eidem BW, Cetta F, Falkensammer CB, Huhta JC, Kleinman CS 2003 Autoregulation of cerebral blood flow in fetuses with congenital heart disease: the brain sparing effect. Pediatr Cardiol 24:436-443

12. Shillingford AJ, Ittenbach RF, Marino BS, Rychik J, Clancy RR, Spray TL, Gaynor JW, Wernovsky G 2007 Aortic morphometry and microcephaly in hypoplastic left heart syndrome. Cardiol Young 17:189-195

13. Brenner JI, Berg KA, Schneider DS, Clark EB, Boughman JA 1989 Cardiac malformations in relatives of infants with hypoplastic left-heart syndrome. Am J Dis Child 143:1492-1494

14. Loffredo CA, Chokkalingam A, Sill AM, Boughman JA, Clark EB, Scheel J, Brenner JI 2004 Prevalence of congenital cardiovascular malformations among relatives of infants with hypoplastic left heart, coarctation of the aorta, and d-transposition of the great arteries. Am J Med Genet A 124:225-230

15. Hinton RB, Martin LJ, Tabangin ME, Mazwi ML, Cripe LH, Benson DW 2007 Hypoplastic left heart syndrome is heritable. J Am Coll Cardiol 50:1590-1595

16. Fishman NH, Hof RB, Rudolph AM, Heymann MA 1978 Models of congenital heart disease in fetal lambs. Circulation 58:354-364

17. Harh JY, Paul MH, Gallen WJ, Friedberg DZ, Kaplan S 1973 Experimental production of hypoplastic left heart syndrome in the chick embryo. Am J Cardiol 31:51-56

18. Lev M 1952 Pathologic anatomy and interrelationship of hypoplasia of the aortic tract complexes. Lab Invest 1:61-70

19. Allan LD, Sharland G, Tynan MJ 1989 The natural history of the hypoplastic left heart syndrome. Int J Cardiol 25:341-343

20. Hornberger LK, Sanders SP, Rein AJ, Spevak PJ, Parness IA, Colan SD 1995 Left heart obstructive lesions and left ventricular growth in the midtrimester fetus. A longitudinal study. Circulation 92:1531-1538

21. Makikallio K, McElhinney DB, Levine JC, Marx GR, Colan SD, Marshall AC, Lock JE, Marcus EN, Tworetzky W 2006 Fetal aortic valve stenosis and the evolution of hypoplastic left heart syndrome: patient selection for fetal intervention. Circulation 113:1401-1405

22. Kleinman CS 2006 Fetal cardiac intervention: innovative therapy or a technique in search of an indication? Circulation 113:1378-1381

23. Miller SP, McQuillen PS, Hamrick S, Xu D, Glidden DV, Charlton N, Karl T, Azakie A, Ferriero DM, Barkovich AJ, Vigneron DB 2007 Abnormal brain development in newborns with congenital heart disease. N Engl J Med 357:1928-1938

24. Mahle WT, Tavani F, Zimmerman RA, Nicolson SC, Galli KK, Gaynor JW, Clancy RR, Montenegro LM, Spray TL, Chiavacci RM, Wernovsky G, Kurth CD 2002 An MRI study of neurological injury before and after congenital heart surgery. Circulation 106:I109-I114

25. Woodward LJ, Anderson PJ, Austin NC, Howard K, Inder TE 2006 Neonatal MRI to predict neurodevelopmental outcomes in preterm infants. N Engl J Med 355:685694

26. Kinney HC, Panigrahy A, Newburger JW, Jonas RA, Sleeper LA 2005 Hypoxicischemic brain injury in infants with congenital heart disease dying after cardiac surgery. Acta Neuropathol 110:563-578

27. Tchervenkov CI, Jacobs JP, Weinberg PM, Aiello VD, Beland MJ, Colan SD, Elliott MJ, Franklin RC, Gaynor JW, Krogmann ON, Kurosawa H, Maruszewski B, Stellin G 2006 The nomenclature, definition and classification of hypoplastic left heart syndrome. Cardiol Young 16:339-368

28. Bonow RO, Cheitlin MD, Crawford MH, Douglas PS 2005 Task Force 3: valvular heart disease. J Am Coll Cardiol 45:1334-1340

29. Kuczmarski RJ, Ogden CL, Guo SS, Grummer-Strawn LM, Flegal KM, Mei Z, Wei R, Curtin LR, Roche AF, Johnson CL 2002. 2000 CDC Growth Charts for the United States: methods and development. Vital Health Stat 11:1-190

30. Nellhaus G 1968 Head circumference from birth to eighteen years. Practical composite international and interracial graphs. Pediatrics 41:106-114 
31. Hadlock FP, Deter RL, Harrist RB, Park SK 1984 Estimating fetal age: computerassisted analysis of multiple fetal growth parameters. Radiology 152:497-501

32. Benson CB, Doubilet PM, Saltzman DH 1986 Intrauterine growth retardation: predictive value of US criteria for antenatal diagnosis. Radiology 160:415-417

33. David C, Gabrielli S, Pilu G, Bovicelli L 1995 The head-to-abdomen circumference ratio: a reappraisal. Ultrasound Obstet Gynecol 5:256-259

34. Hadlock FP, Harrist RB, Carpenter RJ, Deter RL, Park SK 1984 Sonographic estimation of fetal weight. The value of femur length in addition to head and abdomen measurements. Radiology 150:535-540

35. Ertan AK, He JP, Tanriverdi HA, Hendrik J, Limbach HG, Schmidt W 2003 Comparison of perinatal outcome in fetuses with reverse or absent enddiastolic flow in the umbilical artery and/or fetal descending aorta. J Perinat Med 31:307-312

36. Larroche J 1972 Developmental Pathology of the Neonate. Amsterdam: Wiley Inc., pp 85-97

37. Folkerth RD 2007 The neuropathology of acquired pre- and perinatal brain injuries. Semin Diagn Pathol 24:48-57

38. Malik S, Cleves MA, Zhao W, Correa A, Hobbs CA 2007 Association between congenital heart defects and small for gestational age. Pediatrics 119:e976-e982

39. Riddle A, Luo NL, Manese M, Beardsley DJ, Green L, Rorvik DA, Kelly KA, Barlow CH, Kelly JJ, Hohimer AR, Back SA 2006 Spatial heterogeneity in oligodendrocyte lineage maturation and not cerebral blood flow predicts fetal ovine periventricular white matter injury. J Neurosci 26:3045-3055

40. Miller SP, Ferriero DM, Leonard C, Piecuch R, Glidden DV, Partridge JC, Perez M, Mukherjee P, Vigneron DB, Barkovich AJ 2005 Early brain injury in premature newborns detected with magnetic resonance imaging is associated with adverse early neurodevelopmental outcome. J Pediatr 147:609-616

41. de Laveaucoupet J, Audibert F, Guis F, Rambaud C, Suarez B, Boithias-Guerot C, Musset D 2001 Fetal magnetic resonance imaging (MRI) of ischemic brain injury. Prenat Diagn 21:729-736

42. Epstein C, Erickson R, Wynshaw-Boris A 2004 Inborn Errors of Development: The Molecular Basis of Clinical Disorders of Morphogenesis. New York: Oxford University Press, pp 75-89

43. Lian G, Sheen V 2006 Cerebral developmental disorders. Curr Opin Pediatr 18:614620

44. Kostovic I, Jovanov-Milosevic N 2006 The development of cerebral connections during the first 20-45 weeks' gestation. Semin Fetal Neonatal Med 11:415-422

45. Szymonowicz W, Walker AM, Cussen L, Cannata J, Yu VY 1988 Developmental changes in regional cerebral blood flow in fetal and newborn lambs. Am J Physiol 254:H52-H58 